\title{
DYNAMIC ASPECTS OF THE CODE FOR THE DESIGN OF EARTHQUAKE RESISTANT BUILDINGS
}

\author{
R.I. Skinner*
}

\section{SYNOPSIS}

\begin{abstract}
A brief review is given of the most important aspects of the dynamic behaviour of buildings, during elastic and inelastic deformations under earthquake loads, which must be considered for the effective utilization of the NZS 4203 "Code of Practice for General Structural Design and Design Loadings".
\end{abstract}

\section{INTRODUCTION}

When subjected to the irregular cyclic forces imposed by the ground accelerations during earthquakes most buildings respond as resonators with several degrees of freedom. (Newmark and Rosenblueth, 1971). During a moderately severe earthquake a building of adequate strength behaves as a set of lightly damped linear resonators which are conveniently represented by the first few normal modes of vibration of the building. When the earthquake is very severe most buildings suffer inelastic hysteretic deformations in a number of important members. The inelastic deformations give increased deformability and damping, which should limit the buildup of forces and movements to acceptable levels. Motion with severely inelastic member stiffnesses can no longer be approximated by normal modes of vibration.

The aim of the code is to provide buildings with sufficient strength, deformability and energy absorbing capacity to survive moderately severe earthquakes, which are relatively frequent, with little damage and to survive the infrequent very severe earthquake with little likelihood of collapse or of otherwise causing many casualties.

The usual design approach, for moderately severe earthquakes, is to provide sufficient elastic strength to prevent structural damage and to provide non-structural components with sufficient deformability or clearance to minimize damage. Alternatively clearance requirements may be reduced by adopting a stiffer structure.

When designing for very severe earthquakes sufficient strength is provided to limit the number and the extent of the inelastic deformations of essential structural components to levels which will not lead to excessive loss of strength and hence to possible collapse. Also for nonstructural components, whose failure may cause casualties or seriously impede civil defence activities, appropriate strengths and either flexibilities or clearances are

* Head, Engineering Seismology Section, Physics and Engineering Laboratory, DSIR, Lower Hutt. are provided to render such failure unlikely. In practice there is a limit to the inelastic deformation which can be provided, for a given material and loading condition, and this sets a minimum strength requirement for very severe earthquakes. This strength may also be adequate for damage control during moderately severe earthquakes. Since both increased strength and increased inelastic deformability result in increased costs the levels provided should be no more than are adequate to meet the above requirements.

\section{DESIGN EARTHQUAKES}

The acceleration recorded at El Centro 1940, NS component, is typical of horizontal ground accelerations during very severe earthquakes. When the 8 horizontal acceleration records used in DSIR Bulletin 166 (Skinner 1964) each scaled to have the same "spectral intensity" (Housner, 1952) as the above El Centro record then the mean value of the 8 resonator response spectra are similar to the spectra of the El Centro record. The standard deviation of these response spectra is about 0.1 for spectral periods up to 1.0 seconds and is about 0.3 for spectral periods above 1.2 seconds. Similar results were obtained by a group at the Massachusetts Institute of Technology using about 50 records of horizontal acceleration. Hence the El Centro type records upon which the basic seismic coefficients of the 1965. Code were based are typical of the many records obtained during severe earthquakes. However, earthquakes of moderate magnitude, recorded close to the epicentre, will have the maxima of their response spectra at shorter periods while flexible ground will increase the periods of the spectral maxima.

\section{BUILDING MODEL}

The building model for elastic dynamic analysis has the same component flexibilities as the model for elastic static analysis. However, for reinformced concrete the extent of tension cracking is uncertain. Moreover the contribution of floor slabs to beam action is uncertain and is difficult to model.

The building model for inelastic dynamic analysis has the same component loan-deformation characteristics as the model for slowly applied cyclic loads, 
except for moderate strain-rate effects in reinforced concrete. However the loading conditions lead to complex responses. For a reinforced concrete frame which is loaded along both horizontal axes of the building the yield level of columns may depend on an interaction of biaxial bending and shearing together with axial forces. The loading of beams by columns consists of bending and shearing forces, while floor slabs impose torsional loads and also modify the inelastic character of embedded beams to an extent which is difficult to assess. When the inelastic deformations are severe they result in degrading levels of stiffness and strength.

The performance of a building will often depend critically on the relative levels of loading required to form plastic hinges in various members. These levels may control the distribution of hinges between beams and columns and the relative extent of beam-hinge rotation of various storey heights.

It is difficult to match the inelastic character of dissimilar members or of similar members with dissimilar types of loading. Hence for the above reinforced concrete frame building it is difficult to compare the lateral loads required to cause beam hinges with the lateral loads required to cause column hinges since both the character and the loading conditions of the beams and columns are dissimilar. This calls for a considerable margin of column strength if hinges are to be restricted to beams.

In general components may be designed to accommodate moderate inelastic deformations. However provision for increasing inelastic deformations becomes more demanding on design detailing and the performance becomes less certain, except for members with simple conditions of loading. While these comments apply specifically to reinforced concrete members, similar effects may arise in steel members due to local buckling and instability.

\section{DETAILED DYNAMIC ANALYSIS}

Analysis for the earthquake response for a simple building with inelastic components is straight-forward but involves a complex computer program and is very demanding on computer capacity. A detailed time history of the earthquake ground accelerations is required and the dynamic analysis must be performed using numerical integration, with care taken to ensure convergence at each time step and to avoid excessive cumulative errors. The results of interest are the member loads, the number and extent of inelastic deformations of important members, and the maximum deformations of the building. Component strengths may be modified to ensure that inelastic deformations of the building are provided by moderate inelastic deformations of many building members. However component strengths should be balanced to provide for a set of possible earthquakes and hence will not be optimum for any particular earthquake. The effort required with existing computers is so large that such an optimization program would only be attempted for a very important structure. Moreover the appropriate design earthquakes, and the features of the model of the inelastic building, are subject to such uncertainty at present that the use of simpler more approximate methods of analysis would not seriously reduce the reliability of the results.

The reliability of resistance to very severe earthquakes can be increased considerably by choosing structural forms which are somewhat insensitive to the detailed character of an earthquake and which are not prone to sudden collapse as the earthquake level is increased. The design of buildings to ensure beam hinging, the use of specially designed coupled shear walls, and the recently proposed system of base isolation are three approaches aimed at achieving insensitivity to the character and severity of the attacking earthquake.

\section{ELASTIC ANALYSIS AND INELASTIC RESERVE}

A building may be designed and detailed to provide earthquake resistance in an efficient and reliable manner by ensuring the controlled development of inelastic deformations in appropriate members. Such a building may be analysed simply on the basis of an elastic resistance against the scaled down forces of design earthquakes together with a reserve capacity which provides resistance against the full intensity of the design earthquakes. The reserve capacity is provided by the increased deformability and damping conferred on the building by acceptable inelastic deformations of some of its members.

The efficiency and reliability associated with the development of inelastic deformations in building members may be discussed in terms of the performance of a single mass system. When the resistance of the mass supports is bilinear hysteretic (or more generally when it is of Masing type) then the inelastic reserve of resistance against typical earthquakes is approximately equal to the allowable ductility factor, that is the ratio of allowable deformation to the elastic deformation; except that there is a lesser inelastic reserve available for systems with elastic periods of less than 0.4 seconds.

While there has not been a systematic study of the earthquake responses of a wide range of multistorey buildings with inelastic members the following features may be reasonably inferred from existing information (Newmark and Rosenblueth, 1971: Vitiello, 1970). For a typical building with bilinear hysteretic members the reserve capacity, beyond the value at initial yield, is approximately equal to the mean ductility of the inelastic members. Efficiency is therefore achieved by a design which limits the excess of the maximum member ductility over the mean member ductility.

In an efficiently designed building the strength of most of the members does not greatly exceed that required to resist elastically the design earthquakes, reduced by the assumed inelastic reserve. The following conditions should be met in order 
to achieve the greatest practicable inelastic reserve for a given maximum acceptable value for the member ductility demand. Inelastic deformations of members should occur throughout the building and taken together these members should give rise to most of the lateral movement during elastic deformations. Less ambiguously, these "inelastic" members should store most of the potential energy during elastic deformations. Again the building shape under inelastic deformations should be similar to its shape under elastic deformations. Moreover a substantial change in the distribution of horizontal static loads, representing dynamic loads on the building, should give little change in the inelastic deformed shape of the building, so that the maximum ductility demand will be insensitive to changes in the character of the attacking earthquake or the assumed character of the inelastically deforming members. These conditions may be met by a combination of the following provisions.

(i) The inelastic members all yield at approximately the same earthquake intensity.

(ii) The members which remain elastic tend to equalize the ductility of the inelastic members; for example elastic columns inhibit large differences in the inelastic deformations of beams at adjacent levels.

(iii) The bilinear inelastic resistances of members have a substantial second slope, as may be conferred on inelastic beams by associated floor slabs.

For regular buildings these measures will probably limit the maximum member ductility to not more than 1.5 times the mean member ductility.

While member ductility can, within limits, be increased by more expensive detailing, nevertheless reliability is increased by avoiding very high ductility demands. Other means of increasing reliability include limiting ductility to simply loaded members, and controlling the location of hinges to give a building mechanism which is relatively stable under gravity loads and which has a high redundancy of inelastic members.

When effective measures are adopted to limit the maximum ductility demand then the inelastic reserve capacity of a multistorey building is approximately proportional to the maximum acceptable member ductility, as in the case of single-mass systems. For relatively regular buildings this reserve capacity is probably about $70 \%$ of the maximum acceptable member ductility. Hence analysis may be based on elastic responses to design earthquakes, scaled down by the estimated inelastic reserve of earthquake resistance. When the elastic responses of buildings are computed using scaled down earthquakes of "El Centro" type then the base shears, for buildings with fundamental periods between 0.3 and 1.2 seconds, are approximated by a curbe with the shape of the C- values for intermediate subsoils, as given in Figure 1. For short building periods the C-curve is increased above the elastic response to off-set the reduced inelastic reserve available at short periods. The $c$ values are also held constant for building periods above 1.2 seconds as the reserve available from acceptable ductility becomes increasingly uncertain. For very flexible ground the maxima of the earthquake spectra are expected to move to longer periods and hence the C-values are changed accordingly for very flexible ground.

\section{EQUIVALENT STATIC FORCE ANALYSIS}

A study of the maximum elastic responses to earthquakes of many regular and moderately irregular buildings indicates that these maximum elastic responses may be produced approximately by a set of static loads.

A set of horizontal static loads are selected to represent the storey shears, overturning moments and torques imposed on a building by scaled down design earthquakes. The sum of these loads gives the base share $\mathrm{C}_{\mathrm{d}} \mathrm{W}_{t}$, where $\mathrm{C}_{\mathrm{d}}$ is the basic seismic coefficient scaled according to the character and function of the building and to its locality.

The distribution of the horizontal static loads throughout the height and width of a building is obtained by one of several methods.

For buildings which have simple dynamic characteristics the horizontal loads may be distributed throughout the building with an inverted triangle distribution, that is the load at any floor level is proportional to its tributary weight multiplied by the height of the floor above ground level; except that the high moments at the upper levels of buildings with substantial flexural, or tower-like deformations, are represented by concentrating part of the load at the top of the building. The torques arising from moderate design and accidential eccentricities, and from rotation of the ground about a vertical axis, are provided by shifting the point of application of each floor load horizontally from the centre of gravity of the floor.

For highly irregular buildings the distribution of the lateral loads is based on the storey shears, overturning moments and torques, which are derived by spectral modal analysis. The appropriate basic seismic coefficients of Fig.l of the draft Code are used as spectral values. Comparable results would be obtained by using the spectra of Fig.15 in Bull.166 (Skinner 1964), with appropriate period adjustments for flexible ground. Spectral modal analysis may also be adopted for the distribution of lateral loads throughout a building which is not highly irregular.

The significant modal responses are usually combined by taking the square root of the sum of the squares (R.S.S.) of the responses of the individual normal modes. However if two or more significant modes have periods of less than 0.1 seconds their responses should be added algebraically before applying the R.S.S. formula. 
When a pair of significant modes have periods which are greater than 0.1 seconds and which differ by less than $10 \%$ then the R.S.S. values may be seriously in error (Skinner Skilton and Laws, 1965, Penzien 1969). The R.S.S. formula gives values which are too low for modal responses of equal sign and values which are too high for responses of opposite sign. Conversely the algebraic sum of the modal responses is excessive for responses of equal sign and too low for responses of unequal sign. The modes of nearly equal period arise from loosely coupled resonators of nearly equal period. These resonators are usually in appendage and a mode of its supporting building, or almost equal-period translational and torsional modes.

If possible the cause of near periods should be eliminated from the building model for the purpose of determining the overall loads. For example an appendage with a selfperiod close to a building modal period may be assumed rigidly supported except when computing the loads on the appendage. The earthquake records used for this analysis should have smoothed spectra which are similar in shape to the appropriate C-value curve of Fig.l.

There is no systematic data on the inelastic reserve which is available from highly irregular buildings as a consequence of acceptable ductility. However the high damping associated with hysteretic deformation should reduce the dynamic consequences of irregularity, particularly in the case of near-coincident modal periods. On the other hand inelastic deformations may increase the extent of the stiffness irregularities.

\section{PARTS OF BUILDINGS}

In setting the values of the design loads for parts of buildings two important dynamic effects were considered. A maximum local load may exceed considerably the corresponding load from the set of loads which give storey shears, torques and overturning moments. Again the appendage effect may give a double resonant amplification for the loads on parts of buildings (Skinner, Skilton and Laws, 1965, Penzien, 1969). Consideration should also be given to any lack of redundancy in the resisting members of the building part.

\section{STANDARDIZATION OF LEVELS OF \\ EARTHQUAKE RESISTANCE}

While the use of an equivalent static base shear leads to a simple analysis for seismic loads on most buildings, its greatest value lies in the extent to which it leads to uniform levels of earthquake resistance. Buildings detailed by different designers to satisfy the same architectural requirements should have substantially the same earthquake resistance.

A careful choice of material and structural type factors, with due allowance for those features which influence the inelastic reserve of earthquake resistance, are intended to give comparable protection to buildings of different types.

\section{$\underline{\text { ZONING }}$}

On the basis of accepted relationships between recurrence periods and earthquake magnitudes (Dick 1965, Newnark and Rosenblueth 1971), if recurrence periods in one region are 8 times longer than the recurrence periods for corresponding earthquake magnitudes in a second region then design earthquakes for the first region could be of one half the intensity of design earthquakes in the second region, for larger design earthquakes of the intensity at El Centro 1940. There is evidence that the recurrence periods for Zone $\mathrm{C}$ are more than 8 times the corresponding recurrence periods for Zone A (Dick 1965, Newmark and Rosenblueth 1971) but there are several factors which suggest that full advantage should not be taken of these longer recurrence periods.

(i) The data for statistical analysis is meager, particularly for zone c.

(ii) Soil responses are inelastic and microzone effects are therefore more severe during the lower intensity design earthquakes of Zone $C$.

(iii) Very large magnitude earthquakes in Zone A will have potentially damaging intensities in zone $C$, particularly for flexible buildings on flexible ground.

(iv) If there tends to be a common upper limit to the magnitude of eartinquakes for both regions this limit will be of more benefit in the region which adopts high intensity design earthquakes.

\section{IN CONCLUSION}

This paper gives in broad outline those dynamic effects which are most important in the choice of the design procedures recommended in the Earthquake Provisions of the 1975 draft of the code of Design Loads. Particular consequences of these dynamic effects which are described in the commentary to the code are not repeated here.

\section{REFERENCES}

Dick I.D., 1965, "Extreme Value Theory and Earthquakes", Proc. Third World Conf. Earthq. Engrg, Auckland and Wellington, New Zealand, pp 3. 45-53.

Newmark, N.M., and Rosenblueth, E., 1971, "Fundamentals of Earthquake Engineering" Prentice Hall, Englewood Cliffs, N.J., (PP. 356-359).

Penzien, J., 1969, "Earthquake Response of Irregularly Shaped Buildings" Proc. Fourth World Conf. Earthq. Engrg, Santiago, Chile.

Skinner, R.I., Skilton, D.W.C., and Laws, D.A., 1965, "Unbalanced Buildings and Buildings with Light Towers, Under Earthquake Forces", Proc. Third World Conf. Earthq. Engrg, Auckland and Wellington, New Zealand, pp 2. 586-602. 
Skinner, R.I., 1964, "Earthquake-Generated Forces and Movements in Tall Buildings", DISR Bull. 166, Govt. Printer, Wellington, New Zealand.

Vitiello E., 1970, "Seismic Elasto-plastic behaviour of Multistorey Buildings with 'shear-bending type' Resistant Structures" Proc. of Third European Symposium on Earthq. Engrg, pp 581-589.

Housner, G.W., 1952, "Spectrum Intensities of Strong-Motion Earthquakes" "Proc. Symp. Earthquake and Blast Effects on Structures, Earthq. Engrg Research Inst. 